\title{
AÇÃO RADIOPROTETORA DO EXTRATO BRUTO DA CASCA DE Anadenanthera colubrina SOBRE OS EMBRIÕES DE Biomphalaria glabrata
}

\author{
José Luís. F. Sá ${ }^{1,2}$, Williams Nascimento Siqueira ${ }^{1}$, Hianna Arely M. F. Silva. ${ }^{1,2}$, Larissa S. A. Melo, Isabelle Cristinne \\ F. Bezerra ${ }^{3}$, Maíra V. Lima, Dewison R. Pereira ${ }^{1}$, Luiz Alberto L. Soares ${ }^{3}$, Márcia V. Silva ${ }^{2}$, \\ Maria Tereza S. Correia ${ }^{2}$, Ana Maria M. A. Melo. ${ }^{1}$ \\ 1- Departamento de Biofísica e Radiobiologia, CB - UFPE \\ 2- Departamento de Bioquímica, CB - UFPE. \\ 3- Departamento de Ciências Farmacêuticas, CCS- UFPE. \\ luismuma6@gmail.com
}

\begin{abstract}
INTRODUÇÃO
Radiação é energia que se propaga a partir de uma fonte emissora através de meio material ou vácuo, podendo ser classificada como radiação ionizante e não ionizantes (Santos et al., 2013; Okuno, 2013; Siqueira et al., 2014).A radiação ionizante é caracterizada por apresentar energia suficiente para remover elétrons de um á tomo, ocasionando a ionização do mesmo. As radiações não ionizantes, por sua vez, interagem com os elétrons dos átomos ocasionando excitação dos mesmos. As radiações ionizantes são representadas pelas partículas alfa(a), beta(B), prótons, nêutrons, raios gama $(\gamma)$ e raios $X$. São exemplos de radiações não ionizantes os raios ultravioletas, infravermelho, as ondas de radiofrequência, o laser e a luz visível (Bitelli, 2006; Siqueira et al., 2014).

As radiações ionizantes, quando em contato com o sistema bioló gico podem ocasionar danos ao DNA. Estes tipos de energias possuem a capacidade de modificar a fita de DNA gerando erros na divisão celular, podendo ocasionar mutações e até mesmo morte do organismo (Dowd; Tilson, 1999; Santos et al., 2013; Siqueira et al., 2014). Essa interação pode ocorrer de forma direta, quando a radiação age diretamente sobre a biomolecula. Indiretamente a radiação interage sobre molécula de água, produzindo radicais livres qua vão agir sobre as biomoléculas alvo (Santos et al., 2013; Siqueira et al., 2014).
\end{abstract}

$\mathrm{Na}$ literatura há vários relatos de estudos sobre os modelos experimentais para dimensionar os efeitos danosos ocasionados pela radiação nos sistemas biológicos. Como exemplo podem ser citados, bactérias, cultura de células, peixes, concha de moluscos, embriões de Biomphalaria glabrata, fantasmas de hemácias e cultura de linfócitos (Siqueira et al., 2014). De acordo com os estudos, o modelo experimental, utilizando os moluscos de $B$. glabrata e suas proles (embriões) tem fornecido resultados excelentes na avaliação dos efeitos da radiação nos sistemas bioló gicos, por terem os seguintes aspectos: curto ciclo de vida, fácil manutenção em laboratório, baixo custo de manutenção, boa reprodutibilidade e resposta rápida e precisa (Mello et al., 1996; Siqueira et al., 2014).

A aplicação da radiação em diferentes áreas de atuação humana tais como: na medicina, agricultura, indústria tem levantado a necessidade de desenvolver substâncias capazes de proteger o sistema biológico de trabalhadores da área. Estas substâncias são denominadas de radioprotetores, compostos que possuem a propriedade de proteger o tecido vivo, diminuindo os danos a ele causados pela radiação. Sua ação é resultado da interação química entre esses compostos e as espécies reativas do oxigênio geradas pela radiação, impossibilitando os efeitos danosos. Os radioprotetores podem ser classificados como sintéticos e naturais (Santos et al., 2013; Siqueira et al., 2014). Segundos os estudos realizados, os sintéticos têm mostrados ação protetora contra os efeitos nocivos causados pela radiação, porém, esses radioprotetores possuem efeitos colaterais como náusea, vômito e hipotensão (Listet al., 1996; Santos et al., 2013). Desta forma o interesse em pesquisar radioprotetores de origem natural tem aumentado consideravelmente. (Tung-kwanget al., 2010).

Dentre os diferentes vegetais podemos citar a Anadenanthera colubrina, planta da caatinga pertence à família Fabaceae, popularmente conhecida por angico, sendo utilizada no combate a diferentes enfermidades como: gonorreia, leucorreia, no tratamento de febres, úlcera asma e diarreia (Rodrigues et al., 2005; Lima et al., 2014), tendo propriedades químicas indicativas de ser bom radioprotetor frente aos efeitos nocivos ocasionados pela radiação.

Portanto, o objetivo deste trabalho é avaliar ação radioprotetor da casca de Anadenanthera colubrina sobre os embriões de Biomphalaria glabrata.

\section{MATERIAIS E MÉTODOS}

Coleta e armazenamento da planta Anadananthera Colubrina: Amostras de $A$. colubrina casca, foram coletadas em fragmento de caatinga dentro da Empresa Pernambucana de Pesquisa Agropecuá ria (IPA). A área está localizada na cidade de Caruaru, região Agreste do estado de Pernambuco, Brasil $\left(08^{\circ} 14^{\prime} 18.2^{\prime \prime S}\right.$ e $35^{\circ}$ $54^{\prime} 57.1$ "W). Um espécime foi depositado no herbário professor Vasconcelos Sobrinho da Universidade Federal Rural de Pernambuco, número de registro 48663.

Obtenção do extrato da planta Anadenanthera Colubrina:

Após a coleta as amostras foram submetidas à secagem em sombra e ambiente ventilado, em seguida foi triturado em moinhos de faca e peneiradas em uma peneira de malha de $2,0 \times 2,0 \mathrm{~mm}$. 0 extrato bruto da casca de $A$. colubrina (angico) foi obtido pelo método de maceração a partir de $5 \mathrm{~g}$ de massa vegetal em $100 \mathrm{ml}$ de metanol a $80 \%$, a solução foi mantida por 72 horas protegida da luz. 0 extrato foi seco em rota-evaporador (Fisaton modelo 803 ) à pressã o reduzida. A rota-evaporação do extrato é feita para retirada total do solvente metanol a $80 \%$ e a água. 
significativas no número de embriões inviáveis quando comparados a seu controle não irradiado, respectivamente (Santos et al., 2013). Este estudo corabora com os resultados encontrados no nosso trabalho.

Siqueira et al., 2014, analisou o efeito radioprotetor do extrato aquoso da casca e folha de Ziziphus joazeiro irradiados com 2,5 e 5,0 Gy e demonstrou que todos os grupos apresentaram um baixo percentual de embriões malformados ou mortos. E que o grupo irradiado com 5,0 Gy na presença de extrato aquoso da folha exibiu um menor número de embriões inviáveis quando comparados com o grupo controle irradiado também com 5,0 Gy. E o grupo irradiado com 5,0 Gy na presença do extrato aquoso da casca, não apresentou diferença significante em relação ao grupo controle irradiado (5,0 Gy). E que a ação radioprotetor do extrato da folha de Z. joazeiro podem estar relacionada a presença dos metabolitos secundários com potencial antioxidante.

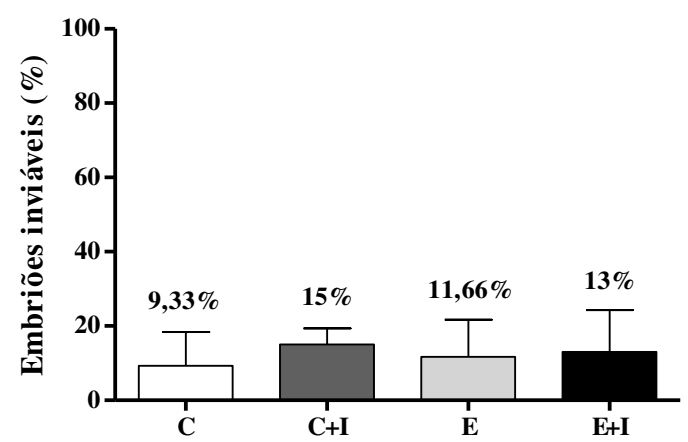

Figura 1: Ensaio realizado com embriões de Biomphalariaglabrataem presença do extrato bruto da casca de $A$. colubrina, na concentração de 125 ppm, submetidos às radiações de 4,0 . As letras presentes no eixo $x$ representam os grupos: controle (C), controle irradiado na presença da água $(C+1)$, extrato bruto na concentração de $125 \mathrm{ppm}(\mathrm{E})$, extrato bruto da casca irradiado a 4,0 Gy $(\mathrm{E}+\mathrm{l})$. Os dados foram expressos \pm E.P.M. (Erro padrão da mé dia), p (Nível de significância) $<0,05$, nos quais os embriões submetidos ao extrato da casca da catingueira não mostraram * (Diferença significativa) em relação ao controle.

\section{CONCLUSÕES}

A análise fitoquímico do extrato bruto da casca de angico mostrou a presença de taninos, açúcares e fenóis. E os resultados obtidos da exposição dos embriões de $B$. glabrata a radiação na presença do extrato da casca de $A$. colubrina na concentração de 125 ppm apresentou uma leve atividade radioprotetora. Sugere-se um estudo mais detalhado sobre a parte química da planta em relação ao enriquecimento da casca de A. colubrina (concentração dos metabolitos responsáveis pala atividade antioxidante) com o objetivo de potencializar a ação radioprotetor.

\section{REFERÊNCIAS}

BITELLI T. Física e dosimetria das radiações, São Paulo: Atheneu; c. 442 p. 5, 2006.

COLACITE, J. Triagem Fitoquímica, Análise Antimicrobiana e Citotó xica e dos Extratos das Plantas: Schinus terebinthifolia, Maytenus ilicifolia Reissek, Tabebuia avellanedae, Anadenanthera colubrina (Vell.) Brenan. Saúde e Pesquisa, 8(3), 509-516, 2015.

DOWD S. B., TILSON E. R. Practical radiation protection and applied radiobiology, Philadelphia: Saunders Company, c1999.

Haslam E. Natural polyphenols (vegetable tannins) as drugs: possible modes of action. Journal Natural Products. 59(2):205-215, 1996.

LEITE J. P., RASTRELLI L, ROMUSSI G. Isolation and HPLC quantitative analysis of flavonoid glycosides from Braizilian beverages (Maytenus ilicifoliaand Maytenus aquifolium). Journal of Agricultural and Food Chemistry. 49(8):3796-3801, 2001.

LIST, A. F.; HESTON, R.; GLINSMANN-GIBSON, B.; CAPIZZI, R. L. Amifostine protects primitive hematopoietic progenitors cytotoxicity. Seminars in Oncology, v. 23, n. 4, p. 58-63, 1996.

LORENZI, H.; MATOS, J. F. Plantas medicinais no Brasil: nativas e exóticas. $2^{a}$ ed. Nova Odessa: Instituto Plantarum de Estudos da Flora, 2002.

MELO A. M. M. A.; OKAZAKI K, KAWANO T. Study of 60Co gamma radiation on Biomphalaria glabrata(Say, 1818) embryos. Journal of Medical and AppliedMalacology. 8:140-141, 1996.

OKAZAKI K, ANDRADE HF, KAWANO T. Effect of ${ }^{60} \mathrm{Co}$ gamma radiation on Biomphalaria glabrata (Mollusca, Gastropoda) embryos: mortality, malformation and hatching. Brazilian Journal of Medical and Biological Research.; 29:1057-1067, 1996.

OLIVEIRA S. M. L., SIQUEIRA, W. N., SÁ, J. L. F., SILVA, L. R. S., DE VASCONCELOS C., D. L., AMÂNCIO, F. F., ALBUQUERQUE M., A. M. $M$. Estudo do efeito radioprotetor do extrato metanólico de Caesalpinia pyramidalis sobre células embrionárias de Biomphalaria glabatra. Scientia Plena, 9(9), 2013.

SIQUEIRA, W. N., SILVA, L. R. S., OLIVEIRA S., M. L., SANTOS, F. T. J., SILVA, H. A. M. F., LACERDA, L. B. N., ...ALBUQUERQUE M. A. M. M. Efeito radioprotetor do extrato de Ziziphus joazeiro sobre embriões de Biomphalaria glabrata submetidos à radiação ionizante. Scientia Plena, 10(9), 2014.

TUNG-KWANG L., O'BRIEN K. F., WANG W., JOHNKE R. M., SHENG C, BENHABIB S. M., WANG T., ALLISON R. R. Radioprotective Effect of American Ginseng on Human Lymphocytes at 90 Minutes Post irradiation: A Study of 40 Cases. The Journal of Alternative and Complementary Medicine. 16(5):561-567, 2010.

RODRIGUES, A. C. DA C.; OSUNA, J. T. A. mudanças morfológica em sementes na espécie Angico (Anadenanthera colubrina (Vell) Brenan Var. cebil [Griseb] Altschul) em diferentes condições ambientais. Mestranda do Curso de Pós-Graduação em Botânica da Universidade Estadual de Feira de Santana, Feira de Santana, Bahia 2005. 